\title{
Os vazios urbanos e o direito à cidade: desafios da implementação do IPTU progressivo em Campos dos Goytacazes/RJ.
}

Bianca Siqueira Gonçalves ${ }^{1}$

\section{RESUMO}

Tendo como cenário a cidade de Campos dos Goytacazes/RJ, este estudo apura a importância do IPTU progressivo enquanto instrumento de democratização do Direito à Cidade, amenizando as disparidades socioespaciais e a especulação imobiliária. É um desdobramento da dissertação, que analisou o processo de formação do espaço urbano da cidade desde 1536 até 2016 . Foram examinados os fatores que favorecem e permitem a existência de vazios urbanos no perímetro da cidade, em regiões valorizadas e munidas de equipamentos urbanos coletivos, e naquelas a serem valorizadas pela ação pública e/ou privada. Evidenciou-se a atuação do capital na configuração do ambiente construído. Buscou-se reforçar as potencialidades da implementação do IPTU progressivo como meio de reintegrar os vazios urbanos existentes e possibilitar a apropriação coletiva do espaço. Concluiu-se que a não aplicação do IPTU progressivo demonstra a complexidade dos interesses em jogo.

PALAVRAS-CHAVE: Cidade; Conflitos; Vazios urbanos; IPTU progressivo.

\section{ABSTRACT}

Using Campos dos Goytacazes/RJ as scenario, it clarifies the importance of progressive IPTU in democratic access to urban land, as an instrument to guarantee the Right to the City. It is an unfolding of the dissertation, which analyzed the process of formation of the urban space of the city from 1536 to 2016.The study analyzed the factors that favor and allow the existence of urban voids in the city perimeter, in regions valued and equipped with collective urban equipment, and in the regions that will be valued by public and/or private action. It evidences the performance of capital in the configuration of the constructed environment. It dedicated to reinforce the potential of IPTU implementation as a means of reintegrating existing urban voids in the city.The inapplicability of the progressive IPTU demonstrates the complexity of the interests at stake.

KEYWORDS: City; Conflicts; Urban voids; Progressive IPTU.

\section{Introdução}

No capitalismo, a cidade é o resultado no espaço dos processos de produção, circulação e consumo. A criação desse espaço é carregada de contradições e tensões, uma vez que nele estão envolvidos os interesses do capital em seus diversos segmentos, da força de trabalho e do Estado (PIQUET e RIBEIRO, 2001). A cidade capitalista é o lugar privilegiado de ocorrência de uma série de processos sociais, onde a reprodução social está condicionada pelo processo de acumulação de capital. Esses processos criam funções e formas espaciais, ou seja, criam atividades e suas materializações, cuja distribuição espacial constitui a própria organização espacial urbana (SANTOS, 2007). A urbanização capitalista é, antes de tudo, uma multiplicidade de processos de apropriação do espaço (BOURDIEU, 1989).

1 Analista Fiscal da Secretaria de Fazenda do Estado do Rio de Janeiro. Mestre em Planejamento Regional e Gestão de Cidades pela Universidade Candido Mendes em Campos dos Goytacazes/RJ. Professora na Universidade Candido Mendes em Campos dos Goytacazes/RJ. Brasil. biancasgoncalves@hotmail.com 
Com o neoliberalismo e submetida ao movimento espontâneo do mercado, a cidade passa a funcionar como uma verdadeira empresa e como tal passa a ser conduzida (VAINER, 2011).

Inúmeras são as questões que envolvem o ordenamento urbano. A legislação brasileira dedicou-se a criar uma série de instrumentos para o enfrentamento dos problemas das cidades.

$\mathrm{Na}$ formação das cidades, em geral, grandes porções de terra, urbanizadas ou não, ficam sem ocupação ou uso, seja por interesses imobiliários especulativos, por circunstâncias ambientais ou de infraestrutura. São os chamados vazios urbanos, que bloqueiam o desenvolvimento equilibrado das cidades, impedem o acesso da maioria da população à terra, à medida em que sua imobilização eleva os preços dos terrenos urbanos, frustram a integração da cidade para dentro e para fora, são um obstáculo à apropriação coletiva do espaço urbano e têm sido uma das questões mais importantes na definição de processos efetivos de planejamento urbano (SINGER, 1980).

Quais os elementos que contribuem para a formação dos espaços territoriais vazios (ou vazios urbanos)? Como os vazios urbanos conseguem sobreviver dentro de um espaço territorial concorrido como é a cidade?

Para compreender o processo de formação dos vazios urbanos, é preciso analisar a ação dos diferentes agentes que produzem o espaço urbano e identificar quais os interesses que os motivam. É essencial observar as relações sociais desenvolvidas em um determinado espaço e examinar de que modo elas influenciam os contornos desse espaço. Este artigo é um desdobramento da dissertação de mestrado da pesquisadora, que analisou o processo de formação do espaço urbano da cidade de Campos dos Goytacazes desde 1536 até 2016.

Quando o Estado permite vazios urbanos em áreas povoadas ou localizadas na faixa de expansão urbana da cidade, a capitalização do território urbano prepondera sobre a socialização do espaço, estando as terras à espera da valorização imobiliária para atendimento dos interesses do capital. O que se deseja é justamente o contrário: a promoção pelos governos municipal, estadual e federal de políticas urbanas condizentes com a demanda coletiva e social, por moradia, incluindo todos os elementos da urbanização e do bem-estar universais.

A inserção do capítulo voltado para a política urbana, em especial os artigos 182 e seguintes, na Constituição Federal de 1988; a publicação do Estatuto da Cidade em 2001; e a criação, em 2003, do Ministério das Cidades, demonstra a importância da matéria. Através desses órgãos e instrumentos, é delegada aos municípios a condução do ordenamento da cidade em direção ao desenvolvimento e crescimento sustentáveis. Cabe a eles o cumprimento das diretrizes estabelecidas no Plano Diretor, cuja função é o planejamento da cidade direcionado para as questões sociais, econômicas e ambientais, públicas, coletivas. Não se pode perder de vista que a propriedade privada deverá cumprir sua função social.

O Estatuto da Cidade prevê instrumentos urbanísticos que têm no combate à especulação imobiliária e na regularização fundiária dos imóveis urbanos seus principais objetivos. Os instrumentos são o parcelamento e a edificação compulsórios, o IPTU (Imposto Predial e Territorial Urbano) progressivo no tempo, com fins punitivos para forçar o proprietário de um terreno comprovadamente ocioso ou subutilizado a dar a esse destino que atenda minimamente que seja ao princípio constitucional da "função social da propriedade" e a desapropriação, como solução extrema (SOUZA, 2001). 
A tributação sobre a propriedade imobiliária foi um dos principais instrumentos jurídicos criados para controlar o processo de expansão urbana submetida ao princípio da função social da propriedade e se tornou um instrumento de política urbana. O IPTU progressivo é um instrumento de minimização da segregação urbana, de democratização do Direito à Cidade, do acesso ao solo urbano e da melhoria da qualidade de vida da cidade.

O IPTU progressivo é capaz de colaborar decisivamente para a tarefa de imprimir maior justiça social nas cidades caracterizadas, simultaneamente, por fortíssimas disparidades sócioespaciais e uma especulação imobiliária desenfreada Souza (2001).

É um instrumento de gestão urbana à disposição do Município para que se alcance a função social da propriedade, com a integração do tecido da cidade e a possibilidade de apropriação coletiva do espaço. É especialmente útil na democratização do acesso à terra, na medida em que a concentração reduz artificialmente a oferta de terrenos.

Em termos concretos, uma vez tendo sido introduzida a progressividade do imposto, após notificação, pelo Município, da obrigatoriedade de edificação ou parcelamento, e não tomando o proprietário, transcorrido determinado prazo, qualquer providência, o valor lançado do IPTU virá a sofrer uma constante majoração anual, sob a forma de crescente porcentagem de acréscimo.

Segundo o artigo $7^{\circ}$ do Estatuto da Cidade, a majoração da alíquota terá o prazo de cinco anos consecutivos. O valor da alíquota a ser aplicado a cada ano será fixado em lei específica e não excederá a duas vezes o valor referente ao ano anterior, respeitada a alíquota máxima de quinze por cento. Decorridos cinco anos de cobrança do IPTU progressivo sem que o proprietário tenha cumprido a obrigação de parcelamento, edificação ou utilização, o Município poderá proceder à desapropriação do imóvel, que terá caráter de sanção e ensejará o pagamento em títulos da dívida pública.

Para que os instrumentos de gestão urbana possam ser utilizados pelo Município para fazer valer a função social da propriedade, é necessário que estejam não apenas previstos no Plano Diretor, mas também em legislação específica que os regulamentem.

\section{Objetivos}

Com o foco de interesse na questão urbana, centra-se a análise nos vazios urbanos de Campos dos Goytacazes. A dinâmica que envolve a produção do espaço urbano pode ser vista nessa cidade, que desde a sua fundação foi sendo construída a partir da relação complexa dos diferentes agentes sociais. A cidade cresceu de forma intensa, porém descontínua, o que privilegiou os agentes sociais do setor imobiliário. Conforme a cidade se expande, vazios urbanos evidenciam-se.

O objeto de estudo consiste na relação entre o IPTU progressivo e os elementos contemplados na legislação brasileira sobre o Direito à Cidade, destacando o seu papel na mitigação dos impactos das glebas vazias como obstáculos à consecução desses preceitos, restrito àquelas que se localizam dentro do perímetro urbano do distrito sede de Campos dos Goytacazes.

Por meio de abordagem qualitativa, o estudo visou responder às seguintes questões: 
(i) Quais os mecanismos de construção do espaço urbano que geram a segregação e a perferização sócioespacial na cidade?

(ii) Qual o papel dos vazios urbanos nesse processo?

(iii) O que a legislação brasileira estabelece para o enfrentamento desses problemas, sob os princípios da Função Social da Propriedade e do Direito à Cidade?

(iv) Qual o papel do IPTU Progressivo nesse contexto?

(v) Como se deu a formação do espaço urbano na cidade de Campos dos Goytacazes e onde se localizam os vazios urbanos na área central da cidade?

vi) Tem o Poder Executivo Municipal de Campos dos Goytacazes atribuído eficácia jurídica e social ao IPTU Progressivo?

\section{Metodologia}

Quanto ao recorte espacial da área de estudo, o perímetro urbano do distrito sede de Campos dos Goytacazes/RJ foi eleito como unidade de análise. Para responder às questões da pesquisa, analisou-se o Plano Diretor do Município de Campos dos Goytacazes (Lei $n^{0} 7.972$, de 31 de março de 2008), a Lei Orgânica (de 15 de julho de 2014) e o Código Tributário Municipal (Lei no 4.156, de 16 de setembro de 1983), e suas contribuições para a concretização de função social da propriedade no município, sendo referências a Constituição Federal de 1988, o Estatuto da Cidade, o Código Civil e as normas editadas pelo Conselho das Cidades e pelo Ministério das Cidades.

Para compreender a origem dos vazios urbanos em Campos dos Goytacazes, a pesquisa demandou a triangulação de dados, com análise do objeto sob as perspectivas documental, legislativa e espacial. Para análise espacial, foram estudados mapas, fotografias e realizadas observações in loco dos vazios urbanos, com captura de imagens. Para identificar quem são os titulares dos espaços vazios da cidade, recorreu-se aos Cartórios de Registro de Imóveis.

Para diagnosticar como se materializa a atuação da Administração Pública, foram analisadas as respostas fornecidas em 2016 pela Secretaria Municipal de Fazenda às indagações sobre a arrecadação do IPTU, o percentual dos espaços vazios e dos espaços edificados dentro da malha urbana e a implantação do IPTU progressivo, dentre outras.

\section{Resultados}

Neste estudo, por unidade de análise, escolheu-se o perímetro urbano do distrito sede de Campos dos Goytacazes/RJ. A escolha originou-se a partir da observação da distribuição da malha urbana, onde se constata a existência de importantes vazios, na área mais adensada em termos populacionais e dos investimentos públicos e privados em equipamentos, infraestrutura e serviços. A estrutura urbana da cidade de Campos dos Goytacazes possibilita o estudo empírico do processo de capitalização do espaço urbano e da atuação dos atores públicos e privados na construção do espaço. 
Figura 1: Mapa do Município de Campos dos Goytacazes no Estado do Rio de Janeiro

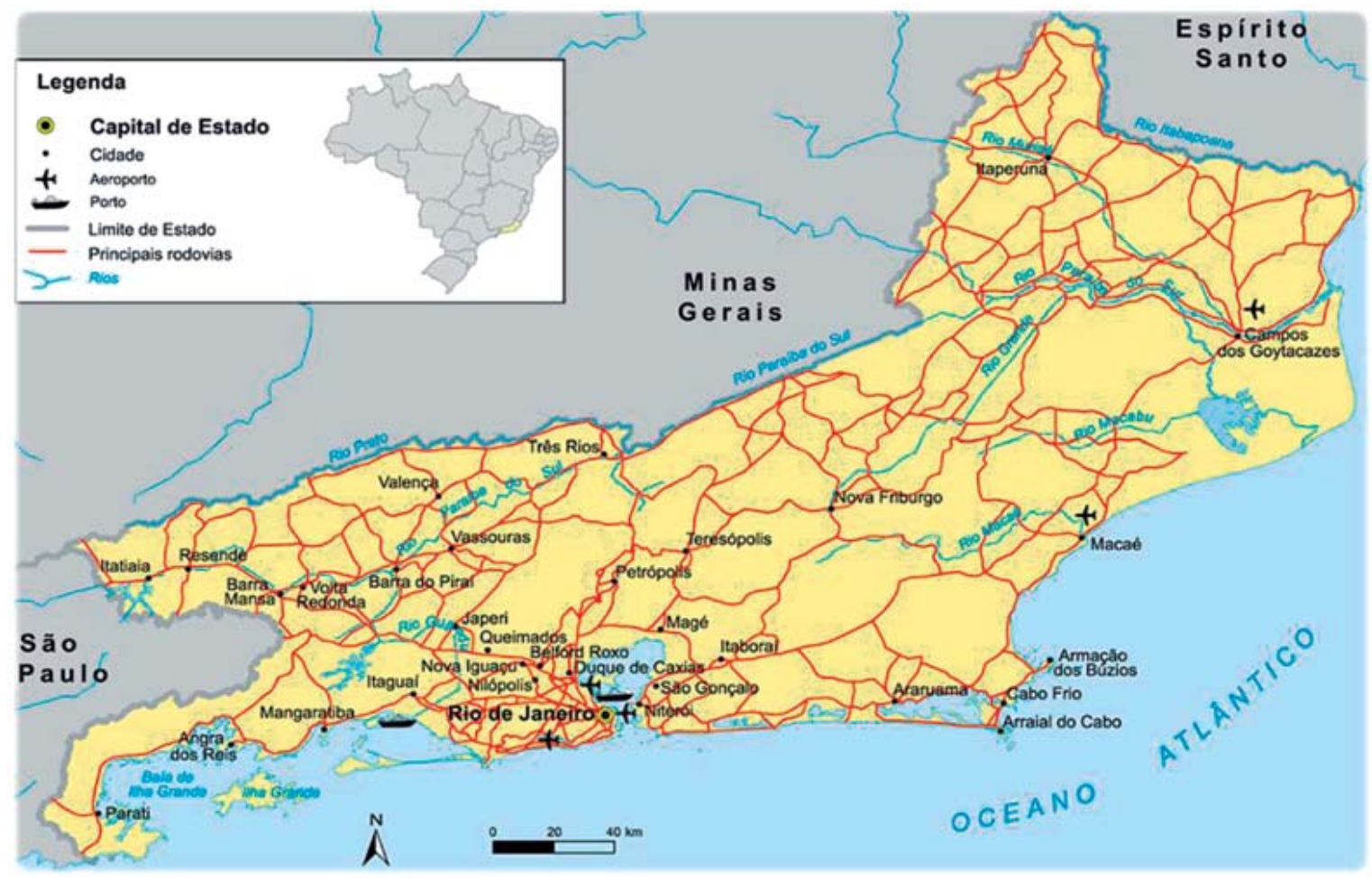

Fonte: Disponível em: 〈http://www.mapas-brasil.net/rio-de-janeiro.htm〉. Acesso em: 17 ago 2016.

Considerando as variáveis sociais que contribuem para a formação do espaço, fez-se necessário pesquisar os vazios urbanos de Campos dos Goytacazes para compreender o que os causam e quais consequências geram para a integração do espaço da cidade.

Os espaços vazios no perímetro urbano de Campos dos Goytacazes são, em sua maioria, formados por glebas de terras das usinas de cana de açúcar e álcool, de fazendeiros e de investidores que se localizam nos arredores da cidade. A partir do Plano Diretor de 1979, com a expansão do perímetro urbano como consequência do crescimento da cidade, muitas dessas propriedades, antes consideradas rurais, passaram a compor o cenário da cidade e se localizar dentro do espaço urbano. Interessante observar que, no século XIX, as usinas se localizavam nos vazios territoriais que se alojavam no entorno da cidade. Na segunda metade do século XX, após o fechamento de algumas delas como consequência da crise econômica do setor, associado ao crescimento do perímetro urbano, elas passaram a ser os grandes vazios dentro da cidade.

Da análise do Mapa dos Vazios Urbanos do Distrito Sede (ALIPRANDI e PINHEIRO, 2015), é possível constatar que a malha urbana da cidade contém significativo número de vazios urbanos. Cabe relembrar que se encontram dentro do perímetro urbano delimitado pelo PDMCG/2008 as terras das usinas São João, São José, Santo Antônio, Queimado, Cambaíba, Cupim, Novo Horizonte, Paraíso, Santa Cruz, Santo Amaro e Sapucaia, bem como as propriedades de antigas fazendas e as propriedades dos atuais investidores. 


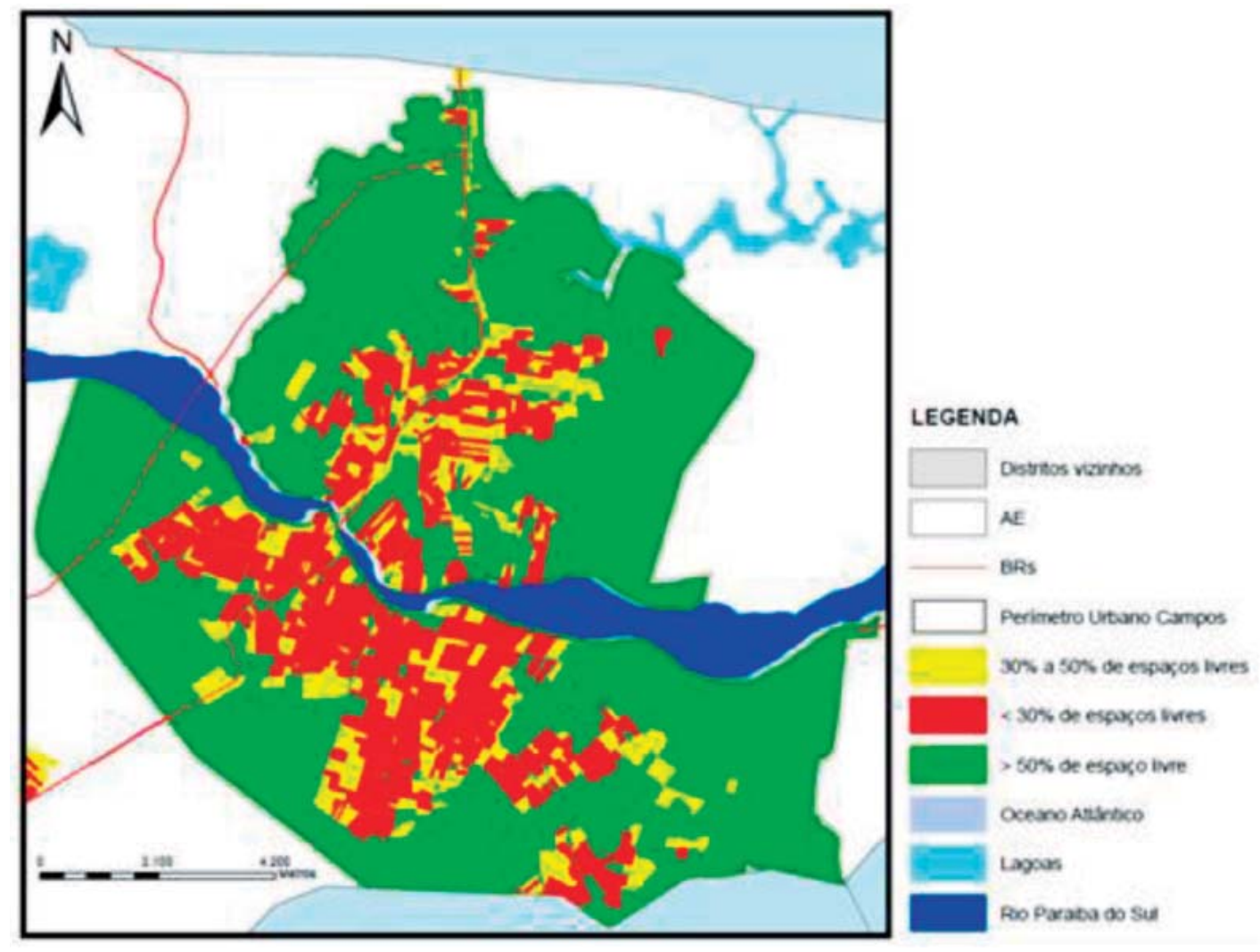

Fonte: Aliprandi e Pinheiro (2015)

A título de exemplo, descreve-se a seguir a atual situação das terras da Usina do Queimado (conforme registros constantes no Cartório do $12^{\circ}$ Tabelionato de Notas e Ofício de Registro de Imóveis em Campos dos Goytacazes/RJ). Localizadas na Avenida Arthur Bernardes, são grandes espaços da paisagem e servem de pastagem, para camuflar a utilização dessas glebas como reserva de valor para investidores e empreendedores imobiliários, que, possivelmente, transformarão essas glebas, esses vazios urbanos, em empreendimentos imobiliários como loteamentos populares ou condomínios fechados.

Oportuno também analisar o estado das terras da Usina Sapucaia (de acordo com os registros constantes no Cartório do $5^{\circ}$ Tabelionato de Notas e Ofício de Registro de Imóveis em Campos dos Goytacazes/RJ). Localizadas na margem esquerda do Rio Paraíba do Sul e subindo seu leito pela BR 356, dentro do Distrito Sede ( $1^{\circ}$ Distrito), estendem-se até o município vizinho de Cardoso Moreira. Possuem extensão de cerca de 2.000 alqueires geométricos e em seu território foram construídos bairros como Parque Aldeia, o conjunto do programa habitacional da prefeitura de Campos dos Goytacazes "Morar Feliz Parque Aldeia" e o bairro Parque Cidade Luz.

Nas terras dessa usina é expressiva a quantidade de áreas alagadiças como consequência da existência de lagoas e brejos. Os projetos urbanísticos (que priorizavam a área central da cidade) e as legislações adotadas ao longo do tempo pelo Poder Público Municipal comprometeram a valorização dessas terras, estigmatizando-as como periferia. Talvez esse seja o motivo de não se encontrar condomínios de classe média alta e alta nesses territórios. Na margem sul do Rio Paraíba estão as terras da predita Usina do Queimado, da Usina Cambaíba e da 
Usina Santo Antônio, situadas nas áreas de expansão da cidade, categoria de terra mais valorizada pelo mercado imobiliário.

Os vazios urbanos de Campos dos Goytacazes não pertencem apenas às famílias dos usineiros, mas também a fazendeiros e a investidores.

Dentre os investidores, há um grupo econômico que, apesar de dedicar-se ao setor hoteleiro, diversifica seus negócios com investimentos em usinas da região Norte Fluminense (como a Usina Cupim, localizada no Distrito Sede). Investiu também na região do bairro Vila da Rainha - localizado entre a Universidade Estadual Norte Fluminense - UENF, o Canal Cambaíba, as margens do Rio Paraíba do Sul e o bairro Jockey). Nessas terras vários empreendimentos foram feitos, como o Clube Saldanha da Gama, o Centro de Eventos Populares CEPOP e os condomínios Palm Spring e Remanso do Paraíba.

Verifica-se que a malha urbana da cidade em estudo é bem centralizada e em constante crescimento. Constata-se verticalização e a busca de aproveitamento máximo do terreno disposto.

A área central possui o tecido urbano mais adensado da cidade. Corresponde ao centro histórico e aos bairros mais ocupados e mais valorizados de Campos dos Goytacazes.

O Distrito Sede ocupa o maior território urbano da cidade, compreendendo praticamente todo o perímetro urbano considerado pelo Plano Diretor Municipal (PDM 2008) e, por sua vez, concentra a maior parte da população campista.

A observação do Mapa de Verticalização (ALIPRANDI e PINHEIRO, 2015) permite concluir que o Distrito Sede possui o maior índice de ocupação e que as quadras são densamente ocupadas. Possui o maior índice de verticalização e crescimento populacional do município, referente aos imóveis que possuem sete pavimentos ou mais. Pode-se observar uma concentração de ocupação dos espaços próximos ao centro antigo. Segundo a Secretaria de Fazenda do Município de Campos dos Goytacazes (SFM), até 2016 foram contabilizados 9843 imóveis construídos no Centro e 3505 imóveis construídos no "novo centro", que é a região da Pelinca. Por via de consequência, há o aumento na verticalização visível. $\mathrm{O}$ adensamento acarreta a supervalorização imobiliária e a saída de moradores com menor renda para as margens do centro urbano.

Quanto aos vetores de crescimento, identifica-se no sentido Goytacazes/Jockey (Leste) os Conjuntos do Programa Morar Feliz e empreendimentos privados. Da Avenida Arthur Bernardes ao Shopping Boulevard (Sul), constata-se a presença de condomínio e loteamentos. Ao Norte, no sentido da BR 101 em direção à Vitória, há o aeroporto e estabelecimentos de abastecimento. Não se identifica expressivo crescimento, muito embora a recente opção pela construção de conjuntos habitacionais populares de grande porte (mais de quinhentas moradias) na área tende a valorizar os terrenos e demandar a implantação de infraestrutura pelo Poder Público municipal, o que poderá configurar um novo vetor de urbanização. No sentido Oeste tem-se a comunidade da Aldeia e tímido crescimento.

Seguindo as disposições da Constituição Federal e do Estatuto da Cidade, Campos dos Goytacazes revisou o Plano Diretor então existente, sancionado pela Lei 5.251, de 27 de dezembro de 1991. Houve a promulgação da Lei 7.972, de 31 de março de 2008, que instituiu o novo Plano Diretor de Campos dos Goytacazes. Contudo, as transformações urbanas e sociais foram pouco expressivas. É que, embora presentes no texto do Plano Diretor, os instrumentos e disposições da legislação federal não foram regulamentados, o que impede a efetivação em Campos dos 
Goytacazes da política urbana instituída no Brasil (aqui cumpre registrar que no texto deste Plano Diretor não há a previsão de prazo para a regulamentação dos instrumentos não autoaplicáveis, como o caso do IPTU progressivo). No que tange à política urbana, Campos dos Goytacazes ainda não conhece o resultado do seu novo Plano Diretor, incapaz de produzir transformações.

É evidente que o aspecto legal não garante o ordenamento da cidade. É preciso mais, para que se atenda ao interesse público e se alcance qualidade de vida para todos.

Com a publicação do PDMCG/2008 (Lei $n^{\circ} 7.972 / 2008$, publicada sete anos após o Estatuto da Cidade - Lei $\left.\mathrm{n}^{\circ} 10.257 / 2001\right)$, houve o cumprimento formal das determinações do Estatuto da Cidade e da Resolução $\mathrm{n}^{\circ} 34$ do Conselho das Cidades.

Constata-se que o Plano Diretor do Município de Campos dos Goytacazes, na Seção II ("DOS INSTRUMENTOS COMPULSÓRIOS E SUCESSIVOS”), Subseção I, trata do "Parcelamento, Edificação ou Utilização Compulsórios". Na Subseção II, dedica-se ao "IPTU Progressivo no Tempo". Ao longo da Subseção III, trata da "Desapropriação com Pagamento em Títulos da Dívida Pública”.

A Lei Orgânica do Município de Campos dos Goytacazes, promulgada em 15 de julho de 2014, dispõe sobre a Política Urbana em seu Capítulo IV (que é uma repetição ipsis litteris do Capítulo III da Lei Orgânica sucedida - promulgada em 28 de março de 1990).

Interessante destacar que o Código Tributário Municipal, de 16 de setembro de 1983 (alterado pelas Leis Municipais $\mathrm{n}^{\circ} 4.241 / 84,4.348 / 84,4.368 / 84,4.587 / 86$, 4.683/87, 4.698/87, 4.848/89, 4.983/90, 4.987/90, 4.988/90, 5.137/90, 5.138/90, 5.238/91, $5.250 / 91,5.252 / 91,5.526 / 93,5.537 / 93,5.538 / 93,6.051 / 95,6.297 / 96,6.299 / 96$, 6.310/96, 6.406/97, 6.506/97, 6.510/97, 6.712/98, 6.753/99 e 7.020/00), prevê sobre o IPTU nos artigos 110 a 120, mas nada diz sobre a progressividade do imposto no tempo.

Embora haja previsão no Plano Diretor e na Lei Orgânica do Município em estudo, carecem os instrumentos de gestão urbana de regulamentação.

Segundo resposta concedida pela Secretaria de Fazenda do Município de Campos dos Goytacazes (SFM) ao requerimento formulado pela pesquisadora no ano de 2016, o IPTU correspondeu a 24,9067\% das receitas municipais, o que demonstra uma expressiva importância desse tributo. O Poder Público municipal admitiu que o IPTU progressivo não é aplicado no município de Campos dos Goytacazes, "porém está em curso uma comissão para a implementação do IPTU progressivo no ano de 2017" (até o presente mês de julho de 2017 nenhuma medida foi adotada).

Quando perguntada sobre o percentual do território, na área urbana da cidade de Campos dos Goytacazes, que se encontra atualmente sem edificação, a SFM respondeu apresentando uma tabela dos imóveis edificados, o que evidencia que não há uma base de dados sobre o percentual do território urbano não edificado. É urgente essa criação, pois tais dados prévios são essenciais para viabilizar a aplicação do IPTU progressivo.

\section{Considerações finais}

Este trabalho buscou contribuir para o debate sobre o espaço urbano como um lugar permeado de contradições e conflitos. A visão constitucionalizada tornou ultrapassado o clássico conceito de propriedade e recolocou o ser humano como preocupação central do Direito, fazendo com que o conteúdo patrimonial do 
direito de propriedade seja contemplado secundariamente. Todo esse processo deriva do princípio constitucional da função social da propriedade, segundo o qual a existência do direito individual à propriedade fica condicionada à utilização conforme o interesse público, alcançando o escopo social deste direito privado.

O estudo do processo de formação do espaço urbano de Campos dos Goytacazes permitiu verificar que as ações realizadas pelo Estado demonstram a condução de um planejamento urbano baseado na consolidação de uma área central, que se desenvolveu a partir de um núcleo urbano desenhado ainda no século XVII, e que foi fortemente influenciada pelas intervenções da indústria açucareira na economia e na sociedade. É possível também constatar o crescimento da área de expansão urbana sobre os terrenos das usinas localizadas próximas ao núcleo central, como Usina do Queimado e Usina Sapucaia.

Nesse processo, a terra concentrada e sob mudança de uso é a principal fonte dos vazios urbanos que vieram a ser formar, contribuindo para um processo de crescimento urbano segregador em relação ao acesso ao solo e aos imóveis, para os segmentos mais pobres e excluídos da população, em Campos dos Goytacazes.

Na cidade de Campos dos Goytacazes, as aparentes ampliações do domínio público sobre a propriedade privada e a formulação de normas legais que pregavam a atribuição de uma função social à terra urbana vêm tendo como objetivo atender os interesses privados de transformação da terra agrícola em urbana, com a ampliação dos espaços periurbanos e a valorização desses espaços perante o mercado, contribuindo para a especulação imobiliária.

O Poder Público Municipal fomentou políticas públicas carentes do intuito de democratização da terra e de apropriação coletiva do espaço. As políticas de urbanização voltaram-se para a higienização do espaço e valorização estética de áreas centrais.

Nesse sentido, buscou-se, neste trabalho, apontar a importância da implementação do IPTU progressivo para justamente alcançar o cumprimento da função social da propriedade.

A cidade é o resultado no espaço dos processos de produção, circulação e consumo. A criação desse espaço é carregada de contradições e tensões, uma vez que nele estão envolvidos os interesses do capital em seus diversos segmentos, da força de trabalho e do Estado.

$\mathrm{Na}$ formação das cidades, em geral, grandes porções de terra, urbanizadas ou não, ficam sem ocupação ou uso, seja por interesses imobiliários especulativos, por circunstâncias ambientais ou de infraestrutura. São os chamados vazios urbanos, que bloqueiam o desenvolvimento equilibrado das cidades, impedem o acesso da maioria da população à terra, à medida em que sua imobilização eleva os preços dos terrenos urbanos, frustram a integração da cidade para dentro e para fora, são um obstáculo à apropriação coletiva do espaço urbano e têm sido uma das questões mais importantes na definição de processos efetivos de planejamento urbano.

A tributação sobre a propriedade imobiliária foi um dos principais instrumentos jurídicos criados para controlar o processo de expansão urbana submetida ao princípio da função social da propriedade e se tornou um instrumento de política urbana. O IPTU progressivo é um instrumento de minimização da segregação urbana, de democratização do Direito à Cidade, do acesso ao solo urbano e da melhoria da qualidade de vida da cidade. Em termos concretos, uma vez tendo sido introduzida a progressividade do imposto, após notificação, pelo Município, 
da obrigatoriedade de edificação ou parcelamento, e não tomando o proprietário, transcorrido determinado prazo, qualquer providência, o valor lançado do IPTU virá a sofrer uma constante majoração anual, sob a forma de crescente porcentagem de acréscimo.

Segundo o artigo $7^{\circ}$ do Estatuto da Cidade, a majoração da alíquota terá o prazo de cinco anos consecutivos. O valor da alíquota a ser aplicado a cada ano será fixado em lei específica e não excederá a duas vezes o valor referente ao ano anterior, respeitada a alíquota máxima de quinze por cento. Decorridos cinco anos de cobrança do IPTU progressivo sem que o proprietário tenha cumprido a obrigação de parcelamento, edificação ou utilização, o Município poderá proceder à desapropriação do imóvel, com pagamento em títulos da dívida pública.

O IPTU progressivo é capaz de colaborar decisivamente para a tarefa de imprimir maior justiça social nas cidades caracterizadas, simultaneamente, por fortíssimas disparidades sócioespaciais e uma especulação imobiliária desenfreada.

É um instrumento de gestão urbana à disposição do Município para que se alcance a função social da propriedade, com a integração do tecido da cidade e a possibilidade de apropriação coletiva do espaço. É especialmente útil na democratização do acesso à terra, na medida em que a concentração reduz artificialmente a oferta de terrenos.

Importante destacar que o IPTU Progressivo, embora previsto no PDMCG/2008, em vigor, não está sendo aplicado pela Administradora em exercício. O Poder Público municipal admitiu que o IPTU progressivo não é aplicado no município de Campos dos Goytacazes, "porém está em curso uma comissão para a implementação do IPTU progressivo no ano de 2017”. Entretanto, até o presente mês de julho de 2017 nenhuma medida foi adotada. Com isso, além de não atuar em benefício da justiça e equidade socioespaciais, conforme determina a legislação, age o Poder Executivo Municipal em prejuízo dos cofres públicos: permite que haja perda de receita pela admissão de cobrança do ITR em área urbana (onde deveria ser aplicado o IPTU, e, nas hipóteses legais, o IPTU progressivo). Anui, também, com o exercício abusivo do direito de propriedade pelo proprietário desidioso em relação à coletividade.

A distribuição não equânime da terra reflete-se na formação de discrepâncias sociais: há espaços de segregação tanto da população de baixa renda, que se mantém em áreas menos valorizadas, quanto pelas classes mais abastadas, que se encastelam em condomínios de luxo.

Conclui-se que, se uma política pública ou um instituto jurídico urbanístico não alcança eficácia prática, deve-se ao fato de que: a) os interesses públicos se confundem aos privados em prevalência dos últimos; b) nas cidades, a força do mercado ganha mais expressão que a força do direito ou do justo, e c) há necessidade de mecanismos mais eficazes de garantia da implantação de políticas públicas ou de efetivação de instrumentos de gestão urbana que objetivem a apropriação coletiva do espaço, já previstos em Lei, como o IPTU Progressivo.

Certo é que a falta de regulamentação dos instrumentos coercitivos que existem para dar efetividade à função social da propriedade não é uma questão a ser enfrentada apenas pelo Município de Campos dos Goytacazes.

Embora haja pouca correspondência entre os objetivos traçados nas normas e os resultados atingidos, os avanços normativos não devem ser desprezados. Apesar de ser mais frequente a apropriação do arsenal legal pelos interesses empresariais, o uso dessas normas difunde o conhecimento sobre o Direito à Cidade, tornando-o 
mais do que apenas linguagem discursiva do Poder Público.

A intenção deste estudo não foi buscar as causas da não utilização do IPTU progressivo em Campos dos Goytacazes. Aqui é preciso destacar que há uma lacuna legal que impede a aplicação dessa penalidade constitucional, tendo em vista que o município não editou a respectiva lei específica regulamentadora.

Resta demonstrado o que já foi afirmado neste trabalho: o ordenamento legal não garante o ordenamento social. Vê-se, ademais, que as ações e omissões do Estado são influenciadas pelas relações de poder que coexistem na sociedade. Sem dúvida a positivação da função social da propriedade deve ser considerada um avanço. Entretanto, a lei que responde à questão teórica não esgota a questão da desigualdade estrutural. O aparato legal é resultado dos conflitos existentes e dos embates sociais, mas é limitado, na medida em que não é hábil a solucionar as questões de fundo.

É preciso agir sobre a contradição evidenciada na produção social dos espaços urbanos: a lógica imediata do lucro, chancelada pelo empresariamento do Estado versus as necessidades coletivas. Diante da realidade posta, que nunca percamos a capacidade de nos indignar. E de agir. 


\section{Referências bibliográficas}

ALIPRANDI, Danielly; PINHEIRO, Mariana. Os espaços livres de Campos dos Goytacazes: mapeamento e categorização. In: CONFERÊNCIA DA REDE LUSÓFONA DE MORFOLOGIA URBANA, 4, 2015, 25-26 jun, Brasília-DF. Anais.. Brasília-DF: Universidade de Brasília, 2015. Disponível em: http:// www.fau.unb.br/noticias/57-pnum-2015. Acesso em: 12 maio 2016.

BOURDIEU, Pierre. 0 poder simbólico. Lisboa: DIFEL; Rio de Janeiro: Bertrand Brasil, 1989.

PIQUET, Rosélia; RIBEIRO, Ana Clara Torres. O desenvolvimento urbano em questão. 2.ed. Rio de Janeiro: IPPUR/UFRJ, 2001.

SANTOS, Milton. O espaço do cidadão. 7. ed. São Paulo: EDUSP, 2007.

SINGER, Paul. O uso do solo urbano na economia capitalista. Boletim Paulista de Geografia, São Paulo, n. 57, 1980. Disponível em: <eduem.uem. br/ojs/index.php/BolGeogr/article/download/12894/7363>. Acesso em: 13 jul 2016.

VAINER, Carlos. Cidade de Exceção: reflexões a partir do Rio de Janeiro. Disponível em:<https://br.boell.org/sites/default/files/downloads/carlos_ vainer_ippur_cidade_de_excecao_reflexoes_a_partir_do_rio_de_janeiro. pdf $>$. Acesso em: 15 jul. 2016. 